\title{
English as a Medium of Instruction: The Case of Technology-Related Classrooms
}

\author{
Ranec A. Azarias, ${ }^{1, *}$ \\ ${ }^{1}$ Ilocos Sur Polytechnic State College \\ *Email: ranecaz@gmail.com
}

\begin{abstract}
English as a Medium of Instruction (EMI) has been an emerging global phenomenon giving birth to various studies. Reviewed studies revealed a dearth of studies on multilingual and technology-related classroom settings. In such lights, this qualitative case study was conducted to describe the used of EMI in the context of multilingual and technology-related classrooms. Through interviews with 16 teachers and following member checking procedures, the cool and warm analyses of interview transcripts revealed that teachers have difficulty in speaking fluent English, eliciting interactions, and explaining lessons when using EMI. The rich sharing of the teachers on their mechanisms in using EMI in their technology-related classrooms yielded the KASAMA Framework: Knowing Your Students, Aligning Objectives and Content/Activities, Simplifying Content, Asking Questions, Making Students Use English, Applying Correct Language Mechanics and Grammar. This study concludes that teachers remain steadfast and flexible in addressing the demands of learners and the teaching-learning process as EMI flourishes and challenges pervade. In so doing, higher education institutions (HEIs) should ensure and include continuous EMI trainings for technology courses. To do this, various future investigations should be conducted to provide more eidetic portraits of EMI in the Philippine HEIs.
\end{abstract}

\section{Keywords: English language use, industrial education, language instruction, technical education}

\section{INTRODUCTION}

In the teaching and learning process, a certain language as the medium of instruction plays a vital role in ensuring success in the delivery of instruction. This has given birth to various policies on what language should be used in teaching. One of these policies is the use of English as Medium of Instruction (EMI). EMI is characterized by the use of English in teaching academic course in areas in which English is not the mother tongue of most population [45].

With growing fame and demand of EMI, various higher educational institutions have adapted and crafted policies making it a global phenomenon. These moves can be attributed to the fact that using EMI can help promote international mobility and improve the language skills of teachers and students [18]. Similarly, The use of EMI stems from the perceived need to internationalize the university to increase its prestige and attract foreign students, as well as the status of English as an international lingua franca, particularly in the field of research publications [45]. In fact, many universities are rushing to offer both tertiary and postgraduate degree programs which use EMI [24] [44].

In addition, studies on EMI emerged as it continues to become global phenomenon. Some common foci of studies are attitude and perception towards EMI, and the problems associate with EMI implementation. In fact, majority of learners believed that learning through English offers no difficulties when they were learning [26]. Also, students perceived English medium courses as satisfactory [15]. This positive attitude towards English language was because of its importance as an international language [13].

Furthermore, educators wanted English no matter what it cost their students [5]. This accentuates the fact that EMI has been perceived to be constructive to the student. In the lights of the pedagogical challenges of using EMI, teachers and students were still firmly convinced that the advantages and opportunities of teaching and learning in English overshadowed the disadvantages [30].

In the Philippines, the attitudes of students, teachers, and parents toward English and Filipino as languages of 
instruction were compared. The students and teachers favored using English in instruction while parents chose Filipino because it is the language that they can comprehend [6]. Interestingly, despite conflicting opinions, Filipino students and teachers lucidly preferred for the use of English in education because of the perceived usefulness of English in development, learning, and communication [11].

Contrastingly, some studies revealed negative attitude towards EMI. It was revealed that students disliked English-medium lecture [41]. Also, students' instrumental orientation toward English was evident [43]. Despite wanting to go away with EMI, students were still positive about the significance of English as linguistic capital [5]. Notably, some parents believed that English language is a barrier for second language speakers because it impedes expression and creativity of ideas among their children [19].

Meanwhile, some problems in the use of EMI emerged. These include scarce opportunities for suitable language training and inadequate language skills of learners and some teachers [25]. Other issues include difficulty finding teachers who are willing and able to teach in English, inadequate support for students with insufficient language skills, trouble meeting the diverse needs of a multinational student body in EMI classes, difficulty finding support EMI secretarial service, and lack of an appropriate remuneration system for EMI teachers[63]. Clearly, the rise in problems has accelerated and several commentators and researchers have pointed out the dangers [40] [31]. Despite the problems associated with EMI, it is undeniable that the scope and role of English have grown a lot in recent decades due to globalization and simultaneous increase in intercultural exchange and personal mobility [15].

Notably, those studies revealed both sides of EMI and the areas that need further investigations especially in the Philippines context. In fact, the impact of language policy on education and the dynamics of language teaching in the Philippines have been the foci of researches on English as MOI [65] [66]. It is to note that reviewed literatures focused on academic courses and classrooms which revealed a dearth of critical studies on industrial-technical classrooms and other fields. Studies revealed more investigations that should be conducted on challenges and needs of educators in using EMI. Undeniably, the MOI area appears to have not been sufficiently investigated in the Philippine context, although the old problems have apparently persisted [29].

With the aforementioned research gaps and findings from various literatures, this study was formulated to describe EMI in the context of industrial-technical classrooms or technology-related classrooms. In this study, the technology-related classrooms also known as industrial-technical classrooms are those classrooms that train and educate students on technical skills and knowledge on areas such as food technology, automotive technology, computer technology, digital technology, electrical technology, electronics technology, apparel technology and other allied engineering fields. It is to note that these classrooms subject students to national assessments by the Technical Education and Skills Development Authority (TESDA) for them to get national certificates for different competencies in their respective major fields. Nevertheless, the challenges and mechanisms of teachers in using EMI were determined with the hope of formulating a framework in using EMI technology courses.

\section{STATEMENT OF THE PROBLEM}

This qualitative study described the use of English as a Medium of Instruction (EMI) in technology-related degree programs of one state college in Ilocos Sur, Philippines as basis in formulating an EMI framework for technology courses. Specifically, this study answered to the following research questions: (a) What challenges do teachers face in using EMI? (b) What coping mechanism do teachers employ in addressing their challenges in using EMI? (c) What mechanisms do teachers employ when using English language as medium of instruction in terms of: designing lessons; delivering lessons; and, assessing students? (d) What framework in using EMI in technology-related classrooms can be formulated?

\section{METHODOLOGY}

\subsection{Research Design}

The qualitative study employed case study design. A case study is an investigative design found in many fields, especially evaluation, in which the researcher cultivates an in-depth analysis of a case, often an event, program, activity, process or a number of individuals [20]. It explores the study of an issue through one or more cases within limited systems [21]. It seeks to provide a thorough understanding of the cases or a comparison of several issues. The design is appropriate to answer the problems of the study since the issues on hand are the challenges and coping of teachers in using English as medium of instruction (EMI). Finally, the design was appropriate because the study investigated the teachers' mechanisms in using EMI in terms of designing a lesson, delivering a lesson, and assessing students' performances and outputs.

\subsection{Selection and Study Site}

The study was conducted in the six campuses of a state college in Ilocos Sur, Philippines. The college is the only state college in Ilocos Sur having six campuses 
offering to different degree programs. The locale was chosen for it offers participants coming from diverse cultural, social and religious backgrounds that can enrich the corpus of data gathering for the study.

In choosing the participants or key informants of the study, criterion sampling was utilized in which three criteria were set. First, they are teaching technologyrelated courses of students who are enrolled in any of the following degree programs: Bachelor of Science in Industrial Technology, Bachelor in Technical Teacher Education, Bachelor in Technical Vocational Teacher Education, Bachelor of Secondary Education major in TLE, Bachelor of Science in Information Technology or Bachelor of Science in Information Systems, Bachelor of Science in Home Technology, and Bachelor of Science in Hotel and Restaurant Management. Second, they have been teaching for at least five years. Third and last, they are willing to participate in the study.

With the set criteria, 25 teachers were identified. Interestingly, saturation of data led the researcher to 16 teachers only. Data saturation phase of qualitative data analysis is where the researcher continues to sample and analyze data until no new data emerge and all concepts of the theory are well-developed.....and their relation to other concepts are lucidly described [50] which transpires informational redundancy [27][60][33]. Saturation is the most lauded guarantee of qualitative rigor given by the authors [49]. Clearly, this study was not guided by the number of participants, but by data saturation. After all, it was assumed that since no new similarities or differences can be identified, data collection need not continue [3].

\subsection{Data Gathering Instrument}

In gathering the pertinent data, an interview guide containing concepts, definitions, and a priori codes was utilized to formulate questions. The formulated questions from interview guide were transferred to the aide-mèmoire that served as a guide during the interview. These guide questions were validated to ensure that the questions to be asked encapsulate the topic or problems of the study. The study also used robotfoto during the preliminary steps of the study to identify the target participants or key informants. Robotfoto is an instrument designed by the researcher which aimed to elicit the profile of the teachers using the set criteria and other information. Finally, their consent in participating in the study was also sought through the interview consent form.

\subsection{Data Gathering Procedure}

Before the study was started, the researcher waited for the approval of the conduct of the study. Upon receipt of the approval from the office of Vice President for Planning, Information, Research and Extension, the target participants were identified using the robotfoto.
Then, the interview guide and aide-mèmoire were constructed.

In gathering the data, the subsequent steps were accomplished. Each teacher participant who participated or had consented in the study was approached by the researchers to schedule individual interviews. Interviews were conducted through messenger and other online platforms. Due to distance and the pandemic, some participants requested that a copy of the questions be sent to them. After answering, they sent their answers through messenger and friends. Transcriptions were done after every interview session and after the answers were sent to arrive at extended texts. Extended texts refer to the transcribed audio or video recordings [9]. Also, spot-checking was done to avoid transcriptionist effect. Then, the extended texts were returned to the teacher participants and follow up interviews were conducted for more accurate and substantial data; hence, employing member checking procedures. It is to note that the students and colleagues of the participants were asked to validate and confirm their sharing.

Finally, cool and warm analyses were conducted in order to arrive at themes that encapsulated the experiences of the participants. Last, gathered data were treated with outmost confidentiality based on the request of the participants and as it was written in the consent form.

\subsection{Mode of Analysis}

The sharing and verbalizations of the participants were transcribed to arrive at extended texts that were subjected to cool and warm analyses. Cool analysis was conducted by looking into patterns or significant statements from the extended texts to facilitate the next step which is warm analysis [9]. In the warm analysis, significant statements were proof-read and analyzed to formulate data categories and themes [64]. To establish the validity, trustworthiness, and truthfulness of the emerging patterns, member checking procedures (follow up interviews, returning the transcripts to the participants, and dissemination of results to the participants) were done [23].

\section{RESULTS AND DISCUSSION}

From the context of using English as a Medium of Instruction (EMI) in technology-related classrooms also termed as industrial-technical classroom, this study identified the challenges, coping mechanism, and mechanisms of teachers in using English as a Medium of Instruction (EMI) technology teachers. Based on the cool and warm analyses of the extended texts produced from the verbalizations of participants, the challenges and the identified coping mechanism were dubbed as $\mathbf{S E}^{2} \mathbf{A}$ of using EMI (Figure 1): Speaking English Fluently, Eliciting Interaction, Explaining Lessons, and Applying Code-Switching. The challenges are SEE while $\mathrm{A}$ is the coping mechanism. It is to note that challenges refer to the difficulties of teachers in using 
EMI, and coping mechanism is the strategy or technique of addressing the difficulties. Last, the richness of extended text surfaced the mechanisms of teachers in using EMI in terms of designing lessons, delivering lessons, and assessing students (Figure 2).

\subsection{Challenges and Coping in Using EMI}

Speaking English Fluently. In the case of technology-related classrooms, EMI is being used. This is evident not only from the sharing of the participants but also from the instructional materials that they use. With this, teachers are expected to speak in English which facilitating their respective classes, either during face-to-face or online classes. In so doing, result of the analysis revealed that speaking English fluently is a challenge being face by the teachers in technologyrelated classrooms. As a challenge, teachers have the inability to speak English fluently which is described in this study as the lack of ability of teachers to use straight or pure English during their classes. The sample verbalizations below support the claim.

\begin{abstract}
"Honestly, I am not used to speaking English in my class. Every time I use or try to speak English it's just like I am gasping for words. So I stutter because I can't speak straight English, I use Ilokano or Tagalog. I really cannot use English straightly in my class." P3
\end{abstract}

"Technically speaking, it is really challenging and difficult using EMI because I can't speak English straightly in my class.” P8

"With these, I always tend to use Ilokano and Tagalog because I cannot really speak straight English even my students." P9

"I am not good in English so I can't use English during the whole duration of my class." P15

Result of the analysis is congruent to the study which revealed that one of the challenges in using EMI was the lack of competence of teachers in English [51]. Also, teachers had extra challenge of being proficient in English to teach content area using EMI [38]. The finding implies that teacher's English language fluency has important role in the success of EMI. In fact, the challenges of using EMI were attributed to teacher skill in English; the teaching and learning under EMI is strongly influenced by social and cultural factors in the local context, as well as by the limited English language skills of teachers and students [73].

Eliciting Interaction. Every classroom is characterized by exchange of ideas between and among the students and teachers. This is one way for the teachers to avoid the monopoly of talking in their classes. Results revealed that teachers have difficulty of eliciting interactions in their classes when they use EMI. To illustrate, the excerpts from the extended texts are presented.
"During recitation or class discussion, I cannot get responses, or I cannot get my class to interact when questions and my talk are stated in English ... and they cannot express also their ideas in English,..." P1

"For the students, they cannot answer or recite because perhaps they cannot understand the questions or lesson when expressed in English so I need to use Ilokano or Tagalog.” P7

"During discussions, my students don't say a word kapag [if] puro [pure] English. It is as if they are amazed. They don't like to talk if it's pure English." P2

"My students cannot also understand the lesson and cannot interact if English is the only language that I use.” P15

"My students will not recite or even talk if I use straight English. The discussion will become dull. There will be no interaction." P16

The finding supports the study that revealed that inadequate class interaction was one of the challenges in implementing EMI [73]. The finding also agrees to a study that revealed that student engagement is a challenge in both traditional face-to-face classrooms and online courses [42]. Notably, the low or poor participation in the classes is attributed to low level of proficiency [52].

Clearly, the finding suggests the importance of interaction and engaging students through discussion in classroom. Engagement and involvement are the key components in student learning; when students work on experimental tasks in small groups, they can brainstorm, learn from each other, and apply knowledge together [52].Regardless of the content and format of the content delivery mechanism, student engagement is the key to effective teaching and learning [42].

Apparently, discussion during lesson delivery comprises students' interaction. It is not just the teacher doing the talking. The finding also suggests that using EMI is a vital in class discussion. It is to note that discussions promote student engagement and develops critical thinking skills [42], improve communication skills [22], and enhance students' learning [34].

Explaining Lessons. In technology-related classrooms, teachers use English in explaining the lessons. However, they have difficulty in using the English language. This difficulty is characterized by not using English during their classes because of they think that students may not understand them due to the technicality of the concepts or lessons being discussed. As verbalized:

"In explaining the lessons, I cannot use English entirely they will not understand; they will be bored. It's just like you are talking to the air if you use English.” P2 
"I cannot also explain the lesson using straight English because my students cannot understand all the things that I am telling aside from the fact that I struggle using English in my class." P3

"Sometimes students cannot understand the terms so I have to use other terms that they can understand." P6

"My difficulty also is to explain using English since it's very technical that's why I used Tagalog or Ilokano when explaining." P8

The finding supports a study which discovered that explaining lessons in English and low English proficiency level of students were challenges in using EMI [51]. Similarly, students' proficiency and teachers' language abilities were two of the identified EMI challenges facing teachers [67]. Nonetheless, the finding implies that English fluency of students and teachers matters in the success of using EMI.

Notably, the complexity of the technical terminology in the technology courses are results of the advancement of technology in the world giving birth to words that are specific to those courses. This highlights that language is dynamic. It is to note that language is dynamic in a way that language continues to evolve over time as speakers and culture change [37]. The birth of new words like in the case of the technology courses is what the culture of technology needs to convey. With these, it is paramount that teachers explain the concepts or words in way that is best understood by their students.

Applying Code-Switching. From the sharing of the participants, code-switching as coping mechanism was identified. This is the strategy identified by the participants in order to cope with the three identified challenges. This coping is characterized by the use of Filipino/Tagalog and Ilokano inside their classes during their classes. The following statements support the finding:

"I have difficulty sometimes especially if I reach the limit of my vocabulary, I use Tagalog instead." P6

"Sometimes when I think I'm not sure of what to say I'd rather speak Tagalog or English sir...’P7

"I always tend to use Ilokano and Tagalog because I cannot really speak straight English even my students.” P9

"Some students are hard up to understand the lesson with the use of English especially now that it's modular so bridging takes place, so for me as a teacher needs to rephrase the sentences and use other languages like Filipino or Ilokano so that learners could follow." P10

"I use Filipino in my discussion for them to understand." P11
"So I often, use Filipino or Ilokano alongside English to facilitate discussion and better explanation of the lessons." P14

Clearly, the statements show that the use of codeswitching is to facilitate clearer explanation and to express their thoughts. In fact, code switching features include relaxing students, talking about classroom tasks and assessment, and interacting with students [2]. Similarly, code switching is for translation, clearing up, socialization, effective instructions, topic shift, and repetition [32]. Hence, teachers need to code switch and mix in order to maximize the understanding of students and for better classroom discussion.

Finally, classroom participants may use code switch for natural communication purposes [47]. Here, the first language (Ilokano or Filipino in this study) is being utilized by the teachers in giving instructions, eliciting answers, and explaining [46]. They also use it for both managerial and pedagogical purposes [4].

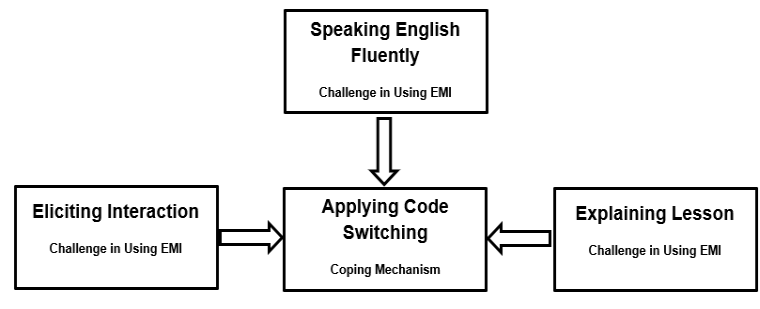

Figure 1. Simulacrum: $\mathrm{SE}^{2} \mathrm{~A}$ of using EMI

\subsection{Mechanisms in Using EMI}

Designing lessons. In technology-related classrooms, designing lessons is a vital aspect of technology instruction. This study looked into this through the rich descriptions and sharing of the participants on their mechanisms in using EMI in terms of designing lessons. Result of the cool and warm analyses transpired two themes: knowing your students and aligning objectives and content/activities.

Knowing your students as one of the mechanism of teachers in using EMI is referred to as the identifying and understanding the diversity or background of the students. Teachers shared that they need to know the level of their students, their abilities, and backgrounds. In so doing, they are given ideas on what to next. As stated:

"So when I know them, I have the idea of how I will design my lessons. I mean will not be giving activities that are too complex." P2

"First, begin with the learner in mind. Know their weaknesses and strengths. For example, know if they can speak English well so that you know if you are going to adjust the content or words in your lesson." P3 
"I consider my students' ability, background, and others. I need to know them so that I know how to attack the lesson or how to explain it. I make sure also to set my objectives ahead. My objectives should match the activities." P6

"I consider my students and their abilities especially their comprehension or English.” P8

"So I need to know my students' level of understanding and skill. Besides, knowing them is the basic thing to do in teaching." P15

The statements suggest that knowing learners is beyond superficial. Teachers who want to maximize learning are expected to navigate the diversity among their learners. In fact, understanding and getting to know students should be the main aim of teaching [68]. Clearly, the significant statements of the participants reiterate that profiling learners helps teacher design their lessons and activities.

Meanwhile, the teachers also identified aligning content, objectives, and activities as one of their mechanism when using EMI in designing lessons. This mechanism is characterized by ensuring that content, objectives, and activities are harmonized. The participants underscored that doing it allows synchronization of all undertakings inside their classes. To justify, the statements below are forwarded.

"After knowing the background of my students, the next thing I do is to make sure that my subject matter, the activities and my objectives jive. They should be aligned so that it will not be a chaos." P1

"I also need to align all the things that I will do in my class. My objectives, lessons, and activities should match so that it will not be a mess." P2

"Make sure that that the activities are aligned with your lessons." P11

"Then, align my objectives with the activities that the students can understand and do." P14

"With that, you can design activities that they can do and that match your lesson objectives." P15

The verbalizations highlight the need for teachers to align content, objectives, and activities as vital components of instruction. By ensuring that the lessons do not go beyond what students can do, they are more likely to master basic skills and study longer [39]. In this way, an aligned instructional plan helps achieve equity goals through making sure that no learners are left behind.

The finding also indicates careful planning alongside setting of objectives in order to facilitate good lessons to students. Planning good lessons must be done because it makes the lessons timely and clear which means that students can be interested and active [62]. When one has objectives in mind, he or she can direct his or her actions in the service of those great objectives [12]. After all, objectives can help learners reflect on their learning when used properly [70].

Delivering lessons. Delivering lessons in technology-related classes requires the use of EMI. In using it, participants shared mechanisms that they used which are themed simplifying content and asking questions. These themes emerged as they share their mechanisms in discussing the lessons and in ensuring interaction in their classes.

Simplifying content is the technique of rephrasing or paraphrasing statements from the lesson. It is also the teachers' acts of substituting technical or complicated words and concepts with simpler words and statements for students to understand the lessons or topics. Simply, it is characterized by using simpler lexicons and syntax. In fact, participants articulated:

"For productive and interactive classroom discussion, I need to simplify my lessons. I mean I need to simplify the complicated or technical words because the students can't understand some technical words." P1

"In short, don't complicate matters. Don't be so English. What I mean is don't insist on using English that are too difficult for students to comprehend. Just use the simpler and basics." P3

"I make sure that the learning topics or concepts are explained in the most simplified way. I do this by explaining the technical terms in common language like instead of using the scientific names for salt and other ingredients, I just say salt, patis for them to understand." P4

"I make sure that my explanations are very easy to understand. I don't complicate matters. As I have said, I use the basic words for them to understand. With this, I can also encourage them to participate because they understood the lesson." P6

"I make sure that my students understand me by simplifying the lessons, and by explaining them in a way that match their level of understanding." P10

The verbalizations explicitly revealed the presence of input modification in technology-related classrooms as manifested in the statements of the participants. Two types of input modification emanate from the verbalizations of the participants: simplification and elaboration. These types of input modification are best understood in the seminal work of Parker and Chaudron (1987). To them, using simpler syntax (in clauses or Snodes per T-unit), shorter utterances (in words or in $\mathrm{T}$ units), simpler lexis (smaller type-token ratios and avoidance of low-frequency vocabulary), preference 
for canonical word order, and deletion of sentence elements or morphological inflections fall under linguistic simplification. Elaboration is characterized by clearer articulation and emphatic stress, slower speech, rhetorical signaling devices, synonyms and restatements, self-repetition, paraphrases, and suppliance of optional syntactic signals (e.g., relative and complement clause markers) which neither simplify nor complexify the surface form; rather, they are elucidations of meaning only which provides better decoding opportunities of communication for the listener/reader . Nonetheless, the participants, as second language learners, use modified language in an attempt to explain and communicate using the English language.

Similarly, simplification focuses on the eradication of complex syntactic structures and intricate words [1]. Accordingly, elaboration aims to increase the intelligibility of content by providing meanings of problem words. It involves reformulating those sentences which contain complicated syntactic structures; thus, advancing semantic aspect.

Notably, the excerpted verbalizations are utterances of non-native speakers of the English language with consideration to their students who are also non-native speakers. The context of the classrooms suggests that the language they use should be both understood by all the actors in the discussion of lessons for communication and understanding to take place. This is done by simplifying complex and technical concepts. The relative simplicity of the languages they use may be attributed to the differences between what needs to be communicated in different sized groups, the situational contexts under in which certain expressions are produced, [8] [7], how languages can adapt to their contextual niche [69], the consequence of the particular social network structure of larger populations [59], and how languages adapt to the structure of environment they are used in [55].

During discussions, the participants shared that they ask questions to their students in order to help facilitate interaction in the class, test their understanding, and get their attention. In so doing, the interaction style between teacher and students can be considered as recycling process characterized by the pattern teacher's questionstudents' responses- feedback [72]. The participants shared:

"I usually pick names from their class cards. I call names and give questions. In this way, the students' attention is for me alone. They will be awakened from daydreaming. So while I am discussing, I ask questions and more follow up questions. Those who can't answer my questions will have to sing or even dance tiktok. I encourage them to say something even a little of everything." P2

"Of course, let them squeeze their minds. Ask them questions. Provoke their thoughts. If you ask questions that they can't answer during discussion, rephrase those questions. Asking questions is one way for me to test if they understood the lesson." P3

"I also make sure that they participate by asking questions during the discussions. This is one way to make sure that they are listening." P11 "I also ask questions to test their
understanding." P15

"In using EMI, I use the graded recitation in a form of question and answer to elicit student interaction during the discussion of the lesson." P16

In asking questions, the English language is being used in which its function is instructional talk. In fact, the teacher's questions can be seen as the most powerful tool to guide, expand, and control communication in the classroom [71]. Notably, recent research studies have shown that it has come to the forefront as a critical component of effective teaching although questioning has long been considered as vital aspect of education [36]. Consequently, effective use of questioning amplifies curiosity, causes increased motivation, and piques interest [17].

Finally, the result as seen in the verbalizations accentuates that teachers' questioning ability and strategies play an important role in delivering lessons. Through this, teachers are able to monitor and maximize the understanding of students if done strategically. In classroom, both teachers and students benefit from strategically structured questioning as a result of careful planning and implementation [56]. Apparently, utilizing variety of techniques for questioning like planning for and scaffolding questions encourages student success and growth in the classroom [57]. Hence, higher order level questions are expected to transpire alongside the lower level questions for a more successful pedagogy and andragogy experiences.

Assessing students. Assessment is a vital process in education that involves both the teachers and his/her students. Teachers plan, design and give or execute assessment activities or task to their students. With these in mind, this study looked into the mechanisms of teachers as they use EMI in assessing students. Analysis of the extended texts revealed two themes as mechanisms of the participants in using EMI as they assess their students: making students use English and applying correct language mechanics and grammar.

The participants share that they let their students use English in answering the tests or quizzed given to them. Noticeably, they argue that students need to use English for future use and because the items are written in English. These manifested from their sharing as stated:

"During written and performance exams, my students should use English not Ilokano or Filipino because whether they like it or not, 
they will use English in their future career or even in their other subjects." P2

"Since I use English in my test and instructions or rubrics, my students should answer or respond using English. Remember that English is the language of instruction in my class though I use Ilokano or Tagalog in explaining." P3

"I ask students to answer in English since I use EMI." P9

"In these tests, the items are in English and they should answer in English.” P10

"I used to ask them many questions and require them to answer in English." P14

The finding manifests that speaking English is a must not only in English or academic classes but also in technology-related classes. In fact, one can improve speaking skills and learn new vocabulary through using English in speaking [61]. Clearly, it is only when speaking English can students will learn to speak English [10]. This highlights the law of use and disuse.

Clearly, the statements suggest that teachers in technology-related classrooms encourage English conversations. English conversation provides the students in practice speaking by the target language; it is used for providing the students to communicate by using target language in a given topic [58]. In so doing, students do not only learn and acquire technology concepts and skills but also language skills in their classrooms.

On the other hand, the participants shared that they usually give written tests and performance tasks in assessing students. Interestingly, the study revealed that ensuring correct language mechanics and grammar are observed when they construct tests and rubrics. Also, the participants noted that this is for the students to have a model of correct English grammar when they answer. They also stated that it is shameful on their part if they grammatical errors. These are evident in the following statements:

"Here, I see to it that the test items and the questions that I use are correct in grammar. I even ask English major or my friend to check my grammar because the students may follow my grammar if it is wrong. My rubrics should also be error free in grammar because they are written in English.” P2

"In making the test, I consider the grammar so that students can have a good example of a sentence in English.” P15

"Since I make them use English, I make sure that my tests are correctly constructed. They should have correct grammar, subject-verb agreement etc. If not totally perfect grammar at least minimal errors. You know, teachers should teach by example." P4

"That is why I also make sure to make my test items correct in grammar. In the performances, I use rubrics. I sometime construct them so I need to be careful in using English especially the grammar because it's shameful if I, the teacher, have errors." P10

Apparently, the English grammar and mechanics are salient component of assessment in technology-related classrooms, either in written or spoken assessment. Using and applying correct grammar helps a person communicate more effectively and precisely and avoid embarrassment [14]. Undeniably, knowledge and mastery of English grammar and mechanics allow teachers to maximize communication and discussion in their classes.

Notably, teacher should not only be proficient in technology courses but also in the use of EMI. In fact, teachers' general proficiency significantly influenced the way they use language in the classroom to promote learning [16]. It should be noted that both speaking and writing well require a level of intelligence and thoughtfulness which is demonstrated by proper grammar [28]. This indicates that teacher's good command of the language form part of the success on technology-related instruction.

\subsection{Mechanism Framework in Using EMI in Technology-Related Classrooms}

In this study, the participants were asked to share their mechanisms in using EMI in their technology courses. This study defines mechanism as techniques or ways of teachers in designing and delivering lessons and in assessing students as they use English as a Medium of Instruction (EMI). Analysis of the extended texts yielded the KASAMA Framework which stands for the mechanism of teachers in using EMI in technologyrelated classrooms (Figure 2): Knowing Your Students, Aligning Objectives and Content/Activities, Simplifying Content, Asking Questions, Making Students Use English, Applying Correct Language Mechanics and Grammar. In designing lessons, teachers employ Knowing Your Students, Aligning Objectives and Content/Activities. In delivering lessons, teachers follow Simplifying Content and Asking Questions. In assessing students, Making Students Use English, Applying Correct Language Mechanics and Grammar are the mechanism that teachers apply. These themes are described and explained in the previous discussions. It is to note that KASAMA is a Filipino word translated as a companion or partner. As such, teachers are expected to be the partners of students in using EMI and in speaking English. As the KASAMA of the students, they are expected to guide and help them in learning in the lights of using EMI 


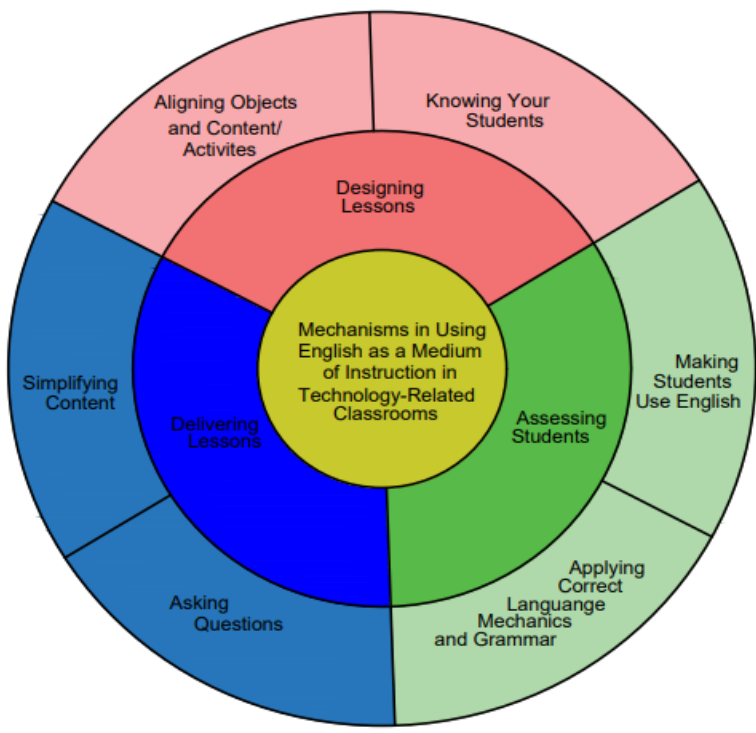

Figure 2. KASAMA Framework: Mechanisms in Using EMI in Technology-Related Classroom

\section{CONCLUSIONS}

From the results of the cool and warm analyses, this study arrived at four conclusions. First, in technologyrelated classrooms, using EMI challenges teachers and students as second language learners as manifested in the identified challenges which are tagged as SEE: speaking English fluently, eliciting interaction, and explaining lessons. Second, teachers in technologyrelated classrooms show rhetorical sensitivity as they apply code-switching in facing the challenges of using EMI. Third, teachers, as they use EMI, adapt flexible mechanisms in terms of designing lessons, delivering lessons, and assessing students which are dubbed as KASAMA: Knowing Your Students, Aligning Objectives and Content/Activities, Simplifying Content, Asking Questions, Making Students Use English, Applying Correct Language Mechanics and Grammar. Fourth, the developed KASAMA Framework in using EMI is applicable in technology-related classrooms with teachers as the primary facilitators of instruction.

\section{RECOMMENDATIONS}

Given the eidetic portrait of using EMI in technology-related courses as revealed in this study, the study recommends that faculty development programs in using EMI through trainings and workshops may be designed to help teachers cope better with the challenges of using EMI. Also, teachers in technologyrelated classrooms may continuously explore and discover other coping mechanisms in dealing with the challenges of using EMI. Further, the identified mechanisms in using EMI may be utilized and improved in response to the evolving demands and diversities of learners. The framework could be utilized also to further understand the context of EMI in multilingual classrooms like the case of this study. Since the study was limited into the identification of the challenges, coping, and mechanisms of the participants in using EMI, future studies should be conducted to determine the seriousness of the challenges in using EMI. Also, future researchers may investigate the techniques and mechanics being used by teachers in code-switching. Input modification techniques may also be investigated. Researchers may also investigate the language needs of teachers as they employ EMI. Finally, the framework could also be used to understand other fields that use EMI to see if same mechanisms transpire.

\section{AUTHOR'S CONTRIBUTIONS}

This research is a single authorship. All the procedures from conceptualization to the finalization of the research manuscript were done by the author himself.

\section{ACKNOWLEDGMENTS}

The researcher wishes to express his profound gratitude to the College President and school officials who made this study possible. Special thanks are also accorded to the participants of the study who willing participated in the study.

\section{REFERENCES}

[1] Ahmadpour Kasgari, Z. (2018). Elaborative text modification vs. input flooding: a case study on non-congruent collocations. Asian. J. Second. Foreign. Lang. Educ., 3 (8). DOI:10.1186/s40862018-0049-z

[2] Ahmad, B. H. \& K. Jusoff. (2009). Teachers' codeswitching in classroom instructions for low English proficient learners, International Language Teaching, 2(2): 49-55. DOI:10.5539/elt.v2n2p49

[3] Aldiabat, K. M., \& Le Navenec, C. (2018). Data saturation: The mysterious step in grounded theory methodology. The Qualitative Report, 23(1), 245 261. DOI:10.46743/2160-3715/2018.2994

[4] Alrabah, S., S. H. Wu, A. M. Alotaibi \& H. A. Aldaihani. (2016). English teachers' use of learners' L1 (Arabic) in college classrooms in Kuwait, English Language Teaching, 9: 1-11. doi:10.5539/elt.v9n1p1

[5] Al-Kahtany, A.H., S.M.G. Faruk\& A.W.Q. Al Zumor (2016). English as the medium of instruction in Saudi higher education: Necessity or hegemony?,Journal of Language Teaching and Research, 7(1): 49-58. DOI:10.17507/j1tr.0701.06

[6] Amamio, L. (2000). Attitudes of students, teachers and parents of RVM schools inmetro Manila toward English and Filipino as media of 
instruction. Unpublished Thesis, UST Graduate School, Manila, Philippines.

[7] Atkinson, M., Kirby, S. \& Smith, K. (2015). Speaker input variability does not explain why larger populations have simpler language. PloS One, 10(6). DOI:10.1371/journal.pone.0129463

[8] Atkinson, M., Smith, K. \& Kirby, S. (2018). Adult learning and language simplification. Cognitive Science, $\quad 42 \quad$ (8): $\quad$ 2818-2854. DOI:10.1111/cogs. 12686

[9] Azarias, R.A. et al. (2020). Free will in Pedagogy: Phenomenologizing the experiences of seasoned teachers. International Academic Journal of Education and Literature, 1(7): 324-329. DOI: 10.47310/iajel.2020.v01i07.008

[10] Beare, K. (2018). English only? An opinion on speaking only English in class?. Retrieved from https://www.thoughtco.com/english-only-in-class1211767

[11] Bernardo, A. B. (2004). McKinley's questionable bequest: Over 100 years of English in Philippine education, World Englishes, 23(1): 17-31. DOI:10.1111/j.1467-971X.2004.00332.x

[12] Best, J. (2019). Why are lesson goals so effective? 3P Learning

[13] Botha, W. (2016). English and international students in China today, English Today 125, 32 (1).DOI: https://doi.org/10.1017/S0266078415000 449

[14] Bronson, S. (2021).Importance of correct grammar.Leaf Group Ltd.

[15] Byun, K., H. Chu, M. Kim, I. Park, S. Kim \& J. Jung (2011). English-medium teaching in Korean higher education: policy debates and reality, High Educ, 62: 431-449. DOI:10.1007/S10734-0109397-4

[16] Canh, L.V. \&Renandya , W.A. (2017). Teachers' English proficiency and classroom language use: A conversation analysis study. RELC Journal, 48(1):67-81. https://doi.org/10.1177/0033688217690935

[17] Caram, C. A. \& P. B. Davis. (2005). Inviting student engagement with questioning. Kappa Delta Pi Record, 42(1): 18-23. https://doi.org/10.1080/00228958.2005.10532080

[18] Cenoz, J. (2009). Towards multilingual education. Basque Educational Research in International Perspective, Bristol, Multilingual Matters. https://doi.org/10.21832/9781847691941

[19] Channa, K.H., S. Memon\& F.A. Bughio (2016). English medium or no English medium: Parental perspectives from Pakistan. Theory and Practice in Language Studies, 6 (8): 1572-1577. DOI:10.17507/tpls.0608.07

[20] Creswell, J.W. (2014). Research design : qualitative, quantitative, and mixed methods approaches, $4^{\text {th }}$ ed. Sage Publications, Inc.

[21] Creswell, J. W. (2013). Research design: Qualitative, Quantitative, and Mixed methods approach. Sage Publications, Inc.

[22] Dallimore, E. J., J, H. Hertenstein\& M. B. Platt. (2008). Using discussion pedagogy to enhance oral and written communication skills. College Teaching, 56(3): 163-172. https://doi.org/10.3200/CTCH.56.3.163-172

[23] de Guzman, A. \& E. Tan (2007). Understanding the essence of scholarship from the lived experiences of a select group of outstanding Filipino researchers. Educational Research Journal, 22(1): 49-65.

[24]Earls, C. W. (2016). Evolving Agendas in European English Medium Higher education: Interculturality, Multilingualism and Language Policy. Basingstoke: Palgrave Macmillan.

[25] Erling, E. J. \& S. K.Hilgendorf (2006). Language policies in the context of German higher education. Language Policy, 5: 267-292. DOI:10.1007/s10993-006-9026-3

[26] Fernández-Costales, A. (2017). Assessing students' perceptions regarding English medium instruction in higher education. DidácticaLengua y literature. DOI:10.5209/DIDA.57129

[27] Francis J.J, M. Johnston, C. Robertson, L. Glidewell , V. Entwhistle , M.P. Eccles , \& J.M. Grimshaw (2010). What is an adequate sample size? Operationalising data saturation for theorydriven interview studies. Psychol.Health, 25(10):1229-1245.

DOI:10.1080/08870440903194015

[28] Frederick, N. (2015). The professional importance of grammar and how it should be taught. People, Ideas, and Things Journal.

[29] Gaerlan, M.J.M. (2016). Learning in a L2: An analysis of less successful Filipino ESL learners' experiences through consensual qualitative research. Proceeding of DLSU Research Congress, 4.

[30] Goodman, B.A. (2014). Implementing English as a medium of instruction in a Ukrainian University: Challenges, adjustments, and opportunities. International Journal of Pedagogies and Learning, 9(2): 130-141. 
[31] Graddol, D. (2006). English next. Retrieved from https://goo.gl/gzL3z4,

[32] Gulzar, M. A. (2010). Code-switching: Awareness about its utility in bilingual classrooms. Bulletin of Education \& Research, 32: 23-44.

[33] Guest G, Bunce A, Johnson L. How many interviews are enough? An experiment with data saturation and variability. Field Methods. 2006;18(1):59-82. https://doi.org/10.1177/1525822X05279903

[34] Hamann, K., P. H. Pollock \& B. M. Wilson. (2012). Assessing student perceptions of the benefits of discussions in smallgroup, large-class, and online learning contexts. College Teaching, 60(2): 65-75.

[35] Hamel, M. (2017).Modifying language without simplification in ELL classrooms.. Retrieved from https://study.com/academy/lesson/modifyinglanguage-without-simplification-in-ellclassrooms.html.

[36] Hannel, I. (2009). Insufficient questioning. Phi Delta Kappan, 91(3): 65-69. https://doi.org/10.1177/003172170909100314

[37] Hansen, J. (2017). What are the five fundamental characteristics of language? ENotes.com Inc.

[38] Hudson, P., Nguyen, T.M.H \& Hudson, S. (2008). Mentoring Vietnamese pre-service teachers in EFL writing.

[39] Hwa, Y., Kaffenberger, M. \& Silberstein, J. (2020). Aligning Levels of Instruction with Goals and the Needs of Students (ALIGNS): Varied Approaches, Common Principles. RISE Insight Series.

[40] Jenkins, J. (2014). Global Englishes: A resource book for students, $3^{\text {rd }}$ ed. London: Routledge.

[41] Joe, Y. \& H. Lee (2013). Does English-medium instruction benefit students in EFL contexts? A case study of medical students in Korea. AsiaPacific Edu Res, 22(2): 201-207. DOI:10.1007/s40299-012-0003-7

[42] Khan, A. Egbue, O., Palkie, B. \& Madden, J. (2017). Active learning: Engaging students to maximize learning in an online course. The Electronic Journal of e-Learning, 15 (2): 107-115.

[43] Lai, M.L. (2013). Impacts of medium of instruction on language attitudes: A case of Hong Kong, AsiaPacific Edu Res, 22: 61-68. DOI:10.1007/s40299012-0025-1

[44] Lasagabaster, D., A. Doiz\& J.M. Sierra (2014). Motivation: Making connections between theory and practice. In D. Lasagabaster, A. Doiz\& J. M. Sierra (eds.), Motivation and foreign language learning: From theory to practice, Amsterdam John Benjamins. P. 173-183.

[45] Macaro, E., S. Curle, J. Pun, J. An \& J. Dearden (2018). A systematic review of English medium instruction in higher education, Lang. Teach, 51(1): 36-76.

[46]Ma, L. P. F. (2019). Examining the functions of L1 use through teacher and student interactions in an adult migrant English classroom. International Journal of Bilingual Education and Bilingualism, 22: $\quad 386-401$ https://doi.org/10.1080/13670050.2016.1257562

[47] Macaro, E. (2009). Teacher use of codeswitching in the second language classroom: Exploring "optimal" use. In Turnbull, A. P. M., DaileyO'Cain, A. P. J. (Eds.), First language use in second and foreign language learning (pp. 3549). Bristol, UK: Channel View Publications.

[48] Mahmoud, A. (2014). Simplification in language learning: What do learners simplify? Studies in English Language Teaching, 2(3): 275-280. DOI:10.22158/selt.v2n3p275

[49] Morse, J.M. (2015). Data were saturated... Qual. Health Res. 25(5):587-588.

[50] Morse, J. M. (2004). Theoretical saturation. In M. S. Lewis-Beck, A. Bryman, \& T. F. Liao (Eds.), The Sage encyclopedia of social science research methods, Thousand Oaks, CA: Sage.

[51] Othman, J. \& Sa at, R.M. (2019). Challenges in using English as a Medium of Instruction: Preservice Science teachers' perspective. Asia-Pacific Education Researcher, 18 (2). 307-316. DOI:10.3860/taper.v18i2.1331

[52] Paolini, A. (2015). Enhancing teaching effectiveness and student learning outcomes. The Journal of Effective Teaching, 15(1): 20-33.

[53] Parker, K., \&Chaudron, C. (1987). The effects of linguistic simplification and elaborative modifications on L2 comprehension. University of Hawaii Working Papers in ESL, 6: 107-133.

[54] Pinar, C. (2017). Challenges in English Medium of Instruction from teachers and students' eyes. International Journal of Languages' Education and Teaching, 5(4): 830-839. DOI:10.18298/ijlet.2096

[55] Perfors, A., \& Navarro, D. J. (2014). Language evolution can be shaped by the structure of the world. Cognitive $\quad$ Science, 38(4), 775-793. DOI: $10.1111 / \operatorname{cogs} .12102$

[56] Peterson, D. S. \& B.M. Taylor. (2012). Using higher order questioning to accelerate students' 
growth in reading. The Reading Teacher, 65(5): 295. https://doi.org/10.1002/TRTR.01045

[57] Phillips, E. (2013). A case study of questioning for reading comprehension during guided reading. Education, 41(1): 110 . https://doi.org/10.1080/03004279.2012.710106

[58] Rahayu, N. (2015). An analysis of students' problems in speaking English daily language program at HusnulKhotimah Islamic boarding school (Unpublished Thesis SyekhNurjati State Islamic Institute).

[59] Reali, F. , N. Chater, , \& M. H. Christiansen (2014). The paradox of linguistic complexity and community size In Cartmill E. A., Roberts S., Lyn H., \& Cornish H. (Eds), Proceedings of the 10th international conference on the evolution of language (EVOLANG X) (pp. 270-279). Singapore: World Scientific Publishing Co. Pte. Ltd.

[60] Sandelowski M. Theoretical saturation. In: Given LM, editor. The SAGE Encyclopedia of Qualitative Research Methods. Thousand Oaks: Sage; 2008. pp. 875-876

[61] Shvidko, E. (2017). Learners' attitudes toward "english-only" institutional policies: Language use outside the classroom. TESL Canada Journal, 34(2): 25-48.

[62] Tess (2015). Lesson planning. Press Book: Granite State College.

[63]Tsuneyoshi, R. (2005). Internationalization strategies in Japan, Journal of Research in International Education, 4(1): 65-86. https://doi.org/10.1177/1475240905050291

[64] Valdez, L.P.M, A.B. De Guzman \& R.L. EscolarChua (2012). Every move counts in learning: Filipino clinical instructors' scaffolding behaviors in teaching medication administration, Nurse Education Today, 33(10). DOI:10.1016/j.nedt.2012.06.011
[65] Vizconde, C. (2011). When language use doesn't see eye to eye: Language practices of teachers and students in a Philippine comprehensive university. KJEP, 8(1): 123-141.

[66] Vizconde, C. (2006b). English language instruction in the Philippine basic education program. RELC Journal, $\quad 37(2)$ : 260-273. https://doi.org/10.1177/0033688206067432

[67] Vu, N.T.T. \& Burns, A. (2014). English as a Medium of Instruction: Challenges for Vietnamese tertiary lecturers. The Journal of Asia TEFL, 11 (3): 1-31.

[68] Walton-Fisette, J.L. (2010). Getting to know your students: The importance of learning students' thoughts and feelings in Physical Education. Journal of Physical Education Recreation and Dance, $\quad 81(71)$ : 1-60. DOI:10.1080/07303084.2010.10598508

[69] Winters, J., Kirby, S. ,\& Smith, K. (2018). Contextual predictability shapes signal autonomy. Cognition, 176, 15-30. DOI: 10.1016/j.cognition.2018.03.002

[70] Wood, D. (2020). Setting \& using effective objectives in the classroom. Retrieved from https://study.com/academy/lesson/settingobjectives-providing-feedback-for-students.html

[71] Yang, M. K. (2006). A critical review of research on questioning in education: limitations of its positivistic basis. Asia Pacific Education Review, 7(2): 195-204.

[72] Yang, M. K. (2002).Exploring the characteristics of students' questioning in class and their educational implications. Korean Journal of Educational Research, 40(1): 99-128. DOI:10.1007/BF03031543

[73] Yang, M. et al. (2019). Challenges and adaptations in implementing an English-medium medical program: A case study in China. BMC Medical Education, 19(15):1-8. DOI:10.1186/s12909-0181452-3 